\title{
Roles of telomeres and telomerase in age-related renal diseases (Review)
}

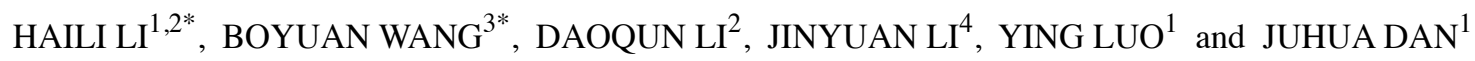 \\ ${ }^{1}$ Laboratory of Molecular Genetics of Aging and Tumor, Medical School, Kunming University of Science and Technology, \\ Kunming, Yunnan 650500; ${ }^{2}$ Department of Human Anatomy, School of Basic Medicine and Institute of Basic Medicine, \\ Shandong First Medical University and Shandong Academy of Medical Science, Jinan, Shandong 250014; \\ ${ }^{3}$ The Key Lab of Sports and Rehabilitation, Faculty of Physical Education, Yuxi Normal University, Yuxi, Yunnan 653100; \\ ${ }^{4}$ Department of General Surgery, Kunming University of Science and Technology, Kunming, Yunnan 650500, P.R. China
}

Received June 27, 2020; Accepted October 30, 2020

DOI: $10.3892 / \mathrm{mmr} .2020 .11735$

\begin{abstract}
Age-related renal diseases, which account for various progressive renal disorders associated with cellular and organismal senescence, are becoming a substantial public health burden. However, their aetiologies are complicated and their pathogeneses remain poorly understood. Telomeres and telomerase are known to be essential for maintaining the integrity and stability of eukaryotic genomes and serve crucial roles in numerous related signalling pathways that activate renal functions, such as repair and regeneration. Previous studies have reported that telomere dysfunction served a role in various types of age-related kidney disease through various different molecular pathways. The present review aimed to summarise the current knowledge of the association between telomeres and ageing-related kidney diseases and explored the contribution of dysfunctional telomeres to these diseases. The findings may help to provide novel strategies for treating patients with renal disease.
\end{abstract}

\section{Contents}

1. Introduction

2. Structural renal changes induced by ageing

3. RCC

4. Ageing-associated CKD

Correspondence to: Professor Ying Luo or Dr Juhua Dan, Laboratory of Molecular Genetics of Aging and Tumor, Medical School, Kunming University of Science and Technology, B308 Biology Science Building, 727 Jingming South Road, Chenggong, Kunming, Yunnan 650500, P.R. China

E-mail: yingluo@kust.edu.cn

E-mail: danjuhua@kust.edu.cn

${ }^{*}$ Contributed equally

Key words: telomeres, telomerase, age-related renal diseases
5. Kidney fibrosis
6. AKI
7. Renal cysts
8. Conclusion

\section{Introduction}

Telomeres have been reported to serve an essential role in the renal ageing process, as they are an age-related component (1). Telomeres are composed of telomere proteins and telomere DNA. Telomere proteins interact with telomere DNA to resist external attacks on the ends of chromosomes and maintain the stability of chromosomes (2). When cells continue to live for a very short period of time, telomere structure and function are disrupted, resulting in genomic instability and increased risk of disease (3). Ageing is a significant risk factor for kidney diseases, such as chronic kidney disease, and epidemiological studies have identified that elderly individuals are predisposed to diverse fluid and electrolyte abnormalities induced by renal diseases (4). The kidneys are significantly affected by profound anatomical and functional changes induced by senescence, and these changes have been discovered to lead to a decreased glomerular filtration rate, reduced urine concentration and dilution abilities, diminished urinary acidification and impaired potassium clearance (5). Numerous studies have demonstrated that cells within the human kidney cortex undergo telomeric shortening over time (6,7). Therefore, determining the multiple signalling pathways, such as p53/p21 and p16INK4a, associated with telomeres and age-related kidney diseases may be important for the treatment of ageing-induced kidney diseases (8).

Telomeres consist of specific short repetitive nucleotide sequences (5'-TTAGGG-3') (Fig. 1) (3). A protein complex termed shelterin, which is made up of telomere protective proteins, is located at the end of chromosomes and maintains telomere structural integrity (2). Shelterin complexes can form telomere-loop (T-loop) by binding specifically to telomeres. Similar to shelterin protein structure function, the T-loop can protect chromosomal ends from end-to-end fusion and degradation $(9,10)$. When a telomere can shorten no more, several 
cellular signals such as DNA damage response, inflammatory and $\mathrm{p} 53 / \mathrm{p} 21$ pathways are activated (11). The reverse transcriptase telomerase is an RNA-dependent DNA polymerase with two primary components: Reverse transcriptase and RNA $(3,12)$. The RNA component of the telomerase sequence is complementary to the telomere template TTAGGG repeat, and the reverse transcriptase component helps to add six-base-pair units to the ends of chromosomes in repetitive cycles $(2,12)$. In this manner, telomerase helps to maintain telomere length (TL) in human stem cells, reproductive cells and cancer cells (13). Telomerase is activated throughout embryogenesis and in numerous types of cancer, but remains inactive during tissue differentiation (14-16). In addition, telomerase is inactivated in the majority of types of mature human cells, which allows telomeres to shorten with every cycle of cell division and eventually lead to chromosomal instability. However, significant differences exist between humans and mice/rodents such as the function of telomerase in cancer and how the state of senescence is reached. For example, by comparing structural and functional changes in ageing rat kidneys in vivo and in vitro, a previous study revealed that rat kidney telomeres did not significantly shorten in aging kidneys, which may contribute to the age-related pathology (17).

While changes are known to occur in the kidneys during the ageing process, the roles of telomeres and telomerase in renal diseases, including renal cell carcinoma (RCC), chronic kidney disease (CKD), glomerulosclerosis, acute kidney injury (AKI) and renal cysts, have gained increasing attention in recent years (Fig. 1) $(18,19)$. Thus, to further understand the causes of renal disease during ageing, the present review aimed to summarise the association between different types of renal disease and related molecular signalling pathways to facilitate the elucidation of novel therapeutic targets for kidney disease.

\section{Structural renal changes induced by ageing}

During the ageing process, the renal parenchyma becomes thinner, which is primarily due to cortical tissue regression, while no significant changes are observed in the thickness of the renal medulla (20). Several changes also occur in the glomerulus that affect the glomerular filtration rate, urine concentration and dilution abilities, and urinary acidification, and some tubulointerstitial alterations have also been noted in ageing kidneys (21). As the understanding of the roles of telomeres and telomerase in renal physiology continues to improve, researchers are actively attempting to elucidate their effects on renal disorders and related diseases (22).

Previously, telomerase deficiency was revealed to reduce the proliferative capacities of glomerular, tubular and interstitial cells; however, telomerase activity differs between humans and mice (23). TL is genetically determined, with the average TL and rate of telomere shortening varying among species. For example, humans are born with shorter telomeres than mice, but mouse telomeres shorten 100 times faster than those of humans (24). It was reported that telomeric shortening limits the recovery capacity following AKI (25). Changes in the kidneys have also been found to be accompanied by vascular changes and blood pressure increases during the ageing process (26). However, although numerous morphological changes, such as the roughness of kidney surface, are observed in ageing organs, none are specifically attributed to kidney pathogeneses. Verzola et al (27) reported that patients with type II diabetic nephropathy had accelerated renal and proximal tubule cell senescence. However, while kidney cell senescence may be induced by telomere shortening, whether it is affected by telomeric loss remains unknown. Aged patients with advanced CKD are known to exhibit numerous age-associated conditions, including myophagism, vascular calcification, premature vascular disease and osteoporosis (28). These age-associated diseases may therefore share mechanisms involved in the ageing process, such as telomere shortening, mitochondrial dysfunction and DNA damage response. Melk et al (8) reported that upregulated $\mathrm{p} 16^{\mathrm{INK} 4 \mathrm{a}}$ expression could directly affect the prognosis of ageing patients with kidney diseases. As changes in kidney function can be quantified in longitudinal studies more readily compared with other organs, kidneys are often used as a model to research the effects on organs during ageing.

\section{RCC}

In recent years, RCC has become the most common type of kidney cancer, accounting for $>90 \%$ of all cases of kidney cancer (29). As RCCs are often diagnosed at an advanced stage, patients with RCC have a poor survival rate, $<8 \%$ (30). TL is known to gradually shorten with age, which may lead to chromosomal instability and subsequent tumorigenesis (31). While some previous studies have demonstrated that a shortened TL promoted poor outcomes for patients with RCC (32), others studies have failed to elucidate such a relationship $(33,34)$. However, Morais and Dias (31) suggested that TL may serve a dual role in RCC, for instance, short telomere length can increase RCC risk in late carcinogenesis, while long telomere length appears to be associated with tumor prognosis in the early stages. Therefore, an increasing number of researchers have also investigated methods, such as reverse transcription PCR, TRF-Southern blotting and fluorescence in situ hybridization, for measuring TL to predict the survival of patients with RCC $(4,35,36)$. Svenson et al (37) used reverse transcription PCR to analyze the TL in the blood cells of patients with kidney cancer instead of the kidney cortex or tumour tissue, and indicated that measuring the TL in the blood may be useful in predicting patient survival. Therefore, as a biomarker of ageing-related diseases, TL should be further studied to elucidate its impact on other tissues (38).

Repressor-activator protein 1 (RAP1) and protection of telomeres protein 1 (POT1) are essential members of the shelterin complex, the expression of which is crucial for telomere maintenance $(3,39)$. Pal et al $(40)$ analysed the gene expression profiles of RAP1 and POT1 in 65 samples of RCC tumour and adjacent normal renal parenchymal tissues. The RAP1 mRNA expression was found to be significantly increased with the grade and subtype of RCC, whereas POT1 expression levels were upregulated in tumour tissues compared with the corresponding normal renal tissues, but POT1 expression was not associated with grades, stages and subtypes of RCC $(33,39)$.

Telomeres have been reported to serve an important role in the prognosis of patients with cancer, and the level of telomerase activity has been discovered to be maintained in $85 \%$ of 
A
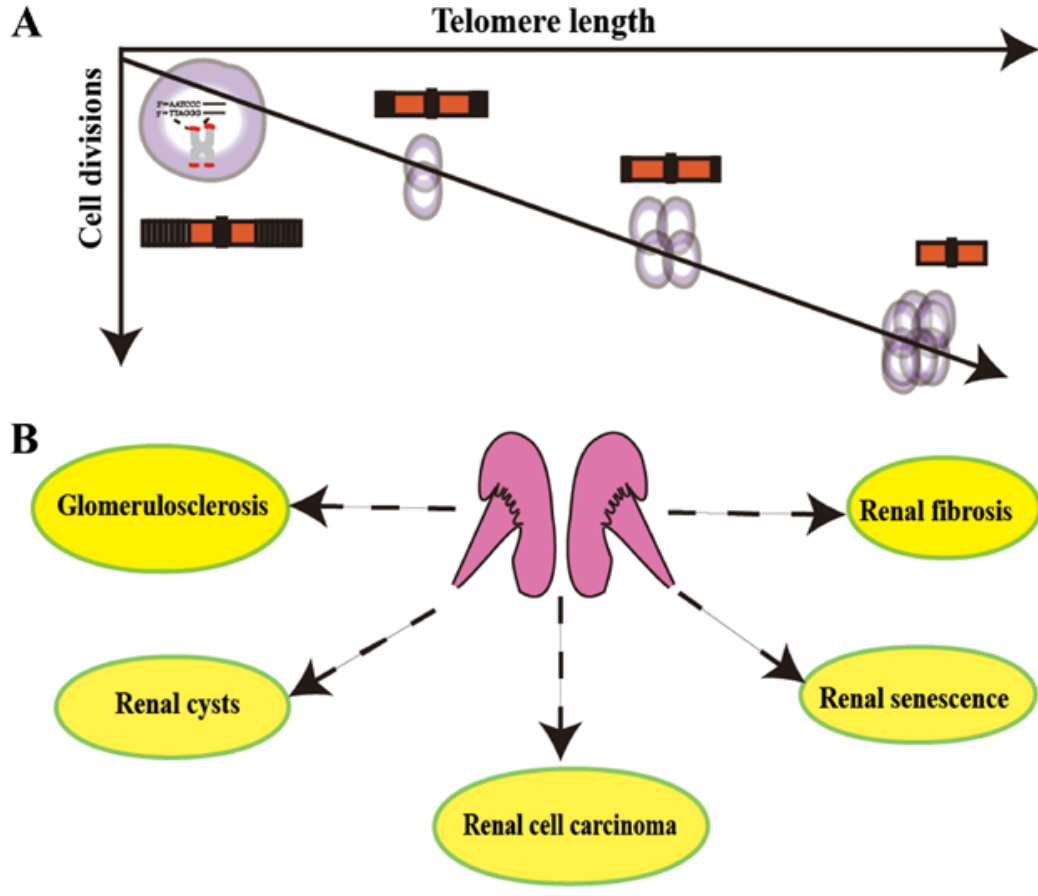

Age-related kidney diseases

Figure 1. Age-related renal diseases can be induced by the shortening of telomeres with cell division. (A) Telomere sequence consists of a G-rich double stranded DNA region. Each time a cell divides, the telomeres shorten the length of an RNA primer, to the point where a functional gene is damaged and the cell stops dividing. Brown and black represent chromosomes and telomeres, respectively. (B) Age-related kidney diseases, such as renal cell carcinoma, chronic kidney disease, glomerulosclerosis, acute kidney injury and renal cysts, that can be induced by telomeric dysfunction. The renal pattern in the middle represents a model of possible kidney disease, such as RCC, CKD and AKI. RCC, renal cell carcinoma; CKD, chronic kidney disease; AKI, acute kidney injury.

malignancies, including RCC (12); however, how telomerase activity is maintained in RCC remains unknown. Human telomerase reverse transcriptase (TERT) is an active component of telomerase that is mainly responsible for its catalytic activity and is known to participate in the maintenance of stem cells, enhancement of DNA repair and promotion of late carcinogenesis (2). Dahse et al (41) demonstrated that the PCR detection of telomerase activity could be used to predict tumour malignancy in patients with RCC. The reported detection of telomerase activity in the majority of RCCs may imply that telomerase activation may be a critical step in the process of RCC (42), and measuring telomerase activity may provide additional information regarding tumour progression and therapeutic strategies.

Numerous further studies are required to elucidate the role of telomeres in the carcinogenesis of RCC. Although an association between telomere-related proteins and the RCC grade and subtype has been well established, the related molecular pathways activated by telomere-related proteins in kidney diseases have not been fully elucidated.

\section{Ageing-associated CKD}

CKD is a major public health problem characterized by poor outcomes, especially with the increasing ageing population (43). Kidney function has been found to decline due to the development of ageing-associated glomerulosclerosis, which is the most common pathological finding in patients with CKD (44). Ageing presents a risk factor for the development of CKD, which is defined by an estimated glomerular filtration rate of $<60 \mathrm{ml} / \mathrm{min}$ per $1.73 \mathrm{~m}^{2}(45)$. The reciprocal relationship between TL and CKD risk has been proven by numerous previous studies (46-48), and while telomere shortening was found to be associated with ageing-related CKD, the interaction is offset by the cellular telomere repair process (4). Telomerase maintains the length and structure of telomeres and extends the cellular life span, and its activity has been suggested to be potentially associated with CKD (49). Despite telomerase activity gradually decreasing with cellular division, telomerase activation holds substantial promise for CKD treatment in the clinical setting (4), as numerous studies have proven the relationship between telomerase activity and CKD stages (50). For example, Kidir et al (49) investigated and followed-up patients with stage 5D CKD and used the TRAP assay to measure telomerase activity in peripheral blood mononuclear cells (PBMCs); the authors concluded that telomerase activity in PBMCs was increased in patients with CKD at risk of advanced stage. However, the study also indicated that telomerase gene polymorphisms may be more related to CKD risks than telomerase activity and TL. It was shown that during the progression of CKD, telomeric RNA component (TERC) rs12696304 and TERT rs2736100 polymorphisms served greater roles in primary glomerulonephritis, end-stage renal disease (ESRD) and CKD in females compared with TL and telomerase activity (48). Moreover, these germline variants were not affected by ageing, diseases or other pathological and physiological environmental elements $(48,51)$. In ESRD, patients exhibited loss of thymic function and telomere attrition, which inhibited the cellular immune system (52). Telomerase activation and telomere 
attrition are usually accompanied by activation of the immune system and the release of inflammatory factors that could be used as biomarkers for the treatment of CKD (53). In addition to inflammation, numerous genes and molecular mechanisms, such as the klotho gene (54) and oxidative stress, have been found to be activated by telomerase activation and telomere attrition during the progression of CKD (55).

Despite the identification of several molecular targets related to telomere dysfunction, numerous therapeutic trials, such as the target telomerase drugs GX301 and GV1001, are not helpful for CKD in older patients. Therefore, telomeres and telomerase activity should be further considered as personalized medicine targets for patients with CKD.

\section{Kidney fibrosis}

Fibrosis can occur in a variety of organs, such as the kidneys, lungs and other major organs under similar fibrosis pathological conditions (56) The main pathological changes underlying fibrosis are the increased accumulation of fibrous connective tissue in organs and decreased numbers of parenchymal cells (57). The deterioration of fibrosis can lead to the destruction of organ structure and functional decline or even failure, which significantly threatens human health (58). Kidney fibrosis is the main pathological feature of chronic kidney failure and manifests as tissue structure disorganisation (59,60). Piñeiro-Hermida et al (61) revealed an association between the development of idiopathic pulmonary fibrosis and telomere dysfunction and telomerase mutations. Likewise, renal fibrosis has been found to be also influenced by cellular ageing-related mechanisms, such as the decline in renal function induced by telomere shortening (62). Cianciolo et al (63) demonstrated that the glomerular filtration rate in humans and dogs decreased over time and while telomere shortening was not definitively the underlying factor, it had an ability to induce ageing-related disease, such as CKD. The length of telomeres is shorten with each cell division, and telomere dysfunction can lead to cell cycle arrest (64). Therefore, telomere dysfunction-induced renal cells with fibrosis are often accompanied by the activation of cell cycle arrest signals (65). Yang et al (66) demonstrated that $\mathrm{G}_{2} / \mathrm{M}$-arrested proximal tubular cells activated by JNK signalling to prevent fibrosis. Thus, telomeres and related molecules may be implicated in renal fibrosis and serve as useful diagnostic biomarkers and therapeutic targets.

\section{AKI}

AKI has become a public health concern because it is associated with high mortality rates. AKI is characterized by a decreased glomerular filtration rate that consequentially results in the deterioration of renal function and ultimately, a considerable percentage of patients requiring dialysis (67). The elderly are particularly susceptible to AKI and demonstrate poor prognoses, which is $<16 \%$ (68). Epel et al (69) identified the relationship between dynamic telomerase activity and acute stressors, and concluded that telomerase activity could be used as a molecular marker for AKI. These data confirmed observations, such as renal regeneration, that telomerase may be a molecular marker in numerous injury models and suggested that the telomere shortening process may be advanced by a single renal insult and potentially accelerated by repeated injuries $(61,70)$. In addition, shortened telomeres were indicated to potentially contribute to increased renal injury and decreased renal recovery following insult (71). Numerous other factors associated with ageing were also indicated to be increased, including reactive oxygen species generation, cell cycle arrest and mitochondrial dysfunction $(72,73)$. Cisplatin (CDDP) is an effective chemotherapeutic agent that is commonly used to treat cancer and has been shown to induce renal toxicity (74). However, the effect of CDDP on AKI in the elderly with shortened telomeres requires further investigation. Shin et al (75) demonstrated that older animals (20-week-old rats) with shortened telomeres treated with CDDP continually had high expression levels of biological markers, such as urinary kidney injury model-1, TIMP metallopeptidase inhibitor 1 and VEGF, which may be helpful in the early diagnosis of elderly patients, who may have shorter telomeres, with CDDP-induced AKI. In the elderly with AKI, telomeres may be used as a molecular maker to evaluate kidney function. The ageing of organs has been identified as the main factor leading to the exacerbation/deterioration of kidney structure during the process of AKI, and cell cycle arrest was discovered to occur not only renal fibrosis, but also in AKI (76). With each cell cycle, telomere repeats are lost because telomerase is not activated in adult human cells. Since the DNA polymerase cannot replicate linear chromosomes from the ends, telomeres are critically shortened (77). In addition, renal ischaemia-reperfusion injury was found to lead to more significant impairment of renal function, and was increased in fourth-generation telomerase-deficient (G4Terc $\left.{ }^{-/}\right)$ mice compared with both wild-type and G1Terc ${ }^{-/}$mice (78). In addition, another previous study reported that critically short telomeres upregulated the expression levels of the cell cycle inhibitors $\mathrm{p} 21$ and $\mathrm{p} 16^{\mathrm{INK} 4 \mathrm{a}}$, and increased renal cell apoptosis accompanied activated ataxia-telangiectasia (79). These data also demonstrated significantly reduced proliferative capacities of tubular, glomerular and interstitial cells. As age-related renal diseases significantly contribute to morbidity by $\sim 18.7 \%$, strategies for preventing these diseases may markedly improve healthy ageing (22). Therefore, renal regeneration following AKI therapy is promising, as telomere shortening can increase cellular senescence and apoptosis, thereby limiting the regenerative capacity in response to injury (80).

\section{Renal cysts}

Renal cysts occur in nephrons and have been discovered to lead to end-stage renal failure due to progressive tubular cystic expansion and loss of typical renal structure and function $(81,82)$. Renal cysts, a condition in which the kidneys are filled with fluid-containing cysts replacing much of the normal renal structure, cause progressive kidney enlargement over time and eventually leads to uremia (83). In addition, fluid within the cysts is derived from glomerular filtrate and transepithelial fluid secretion (84). Renal cysts were also discovered to occur in the development of long-term CKDs and other types of organ dysfunction, such as pancreas and ovary $(85,86)$. For example, Yaghoubian et al (87) observed that patients with abdominal aortic aneurysms had increased renal cyst incidence rates, indicating that renal cysts may be associated with other 
types of disease. In addition, previous research on polycystic kidney disease (PKD) identified numerous of the molecular mechanisms that were closely associated with the occurrence of renal cysts, such as genetic mutations in hepatocyte nuclear factor-1 $\beta$ and polycystin-1/2 (88-90), abnormal renin-angiotensin-aldosterone system activation (91), altered intracellular calcium signalling $(82,92)$, MET oncogene mutations (93), vasopressin receptor upregulation (94), mTOR pathway activation $(95,96)$, c-Myc-derived apoptosis (97), endothelin-1 receptor upregulation (98), TGF- $\beta 1$ and apelin pathway activation (99), VEGF gene variants (100) and dysfunction of the innate immune system (101). According to the results of NCBI literature search, there are a few studies evaluating the relationship between telomere and PKD (102-104). Although there is not sufficient evidence to prove the direct relationship between telomeres or telomerase and renal cysts, the association between telomere dysfunction-induced tumours and PKD was confirmed in our previous study; RNA-Seq and single-sample gene set enrichment analysis was used to identify the gene signatures and pathways. The results have shown that mutant p53 and telomere dysfunction increased the development of PKD (105). In regard to these data, further research should be performed to explore the combination of mutant p53-target and telomere drugs, such as GRN163L and APR-246 in the future $(106,107)$. The application of this combination for renal cyst treatment could enhance renal function and relieve the pain caused by abnormally functioning kidneys.

\section{Conclusion}

Due to the ageing population, ageing-related renal diseases have attracted increasing attention. Extensive studies have revealed that telomeres and telomerase serve important roles in not only normal nephrogenesis, but also in renal cysts, fibrosis, regeneration after AKI, RCC and various CKDs (Fig. 1). Thus, future research should focus on whether telomeres and renal diseases exert a cause or effect role to improve the research and treatment of kidney disease. It should be noted that telomere dysfunction is not always required for the induction of ageing-related renal diseases, and could be due to cumulative environmental stress. Although numerous studies have proven that telomere dysfunction is involved in various types of renal disease in the elderly and the role of telomere maintenance in age-related renal diseases, it is currently unknown whether telomere homeostasis has beneficial effects on the ageing kidney. Thus, further evaluation of the impact of telomere dynamics on the ageing kidney is required. In conclusion, the study of telomeres and telomerase in relation to kidney diseases is only in its infancy and further research questions, such as drug development targeting telomerase will need to be addressed in the future.

\section{Acknowledgements}

Not applicable.

\section{Funding}

This work was supported by the Academic promotion programme of Shandong First Medical University (grant no. 2019QL016) and the Innovation Project of Shandong Academy of Medical Sciences.

\section{Availability of data and materials}

Not applicable.

\section{Authors' contributions}

HL and BW were major contributors in writing the manuscript. DL and JL corrected the English writing. YL and JD read and approved the final manuscript. All authors (HL, BW, DL, JL, YL and JD) read and approved the final manuscript.

\section{Ethics approval and consent to participate}

Not applicable.

\section{Patient consent for publication}

Not applicable.

\section{Competing interests}

The authors declare that they have no competing interests.

\section{References}

1. Shay JW and Wright WE: Hallmarks of telomeres in ageing research. J Pathol 211: 114-123, 2007.

2. Pańczyszyn A, Boniewska-Bernacka E and Goc A: The role of telomeres and telomerase in the senescence of postmitotic cells. DNA Repair (Amst) 95: 102956, 2020.

3. Smith EM, Pendlebury DF and Nandakumar J: Structural biology of telomeres and telomerase. Cell Mol Life Sci 77: 61-79, 2020.

4. Ameh OI, Okpechi IG, Dandara C and Kengne AP: Association between telomere length, chronic kidney disease, and renal traits: A systematic review. OMICS 21: 143-155, 2017.

5. Bolignano D, Mattace-Raso F, Sijbrands EJ and Zoccali C: The aging kidney revisited: A systematic review. Ageing Res Rev 14: 65-80, 2014.

6. Sitaram RT, Cairney CJ, Grabowski P, Keith WN, Hallberg B, Ljungberg B and Roos G: The PTEN regulator DJ-1 is associated with hTERT expression in clear cell renal cell carcinoma. Int J Cancer 125: 783-790, 2009.

7. Svenson U, Gronlund E, Soderstrom I, Sitaram RT, Ljungberg B and Roos G: Telomere length in relation to immunological parameters in patients with renal cell carcinoma. PLoS One 8: e55543, 2013.

8. Melk A, Schmidt BM, Takeuchi O, Sawitzki B, Rayner DC and Halloran PF: Expression of p16INK4a and other cell cycle regulator and senescence associated genes in aging human kidney. Kidney Int 65: 510-520, 2004.

9. de Lange T: A loopy view of telomere evolution. Front Genet 6: $321,2015$.

10. Wood AM, Laster K, Rice EL and Kosak ST: A beginning of the end: New insights into the functional organization of telomeres. Nucleus 6: 172-178, 2015.

11. de Lange T: Protection of mammalian telomeres. Oncogene 21: 532-540, 2002.

12. Nagpal $\mathrm{N}$ and Agarwal S: Telomerase RNA processing: Implications for human health and disease. Stem Cells 2020 (Epub ahead of print).

13. Serakinci N, Graakjaer J and Kolvraa S: Telomere stability and telomerase in mesenchymal stem cells. Biochimie 90: 33-40, 2008.

14. Blagoev KB: Cell Proliferation in the presence of telomerase. PLoS One 4: e2622, 2009.

15. Cong YS, Wright WE and Shay JW: Human telomerase and its regulation. Microbiol Mol Biol Rev 66: 407-425, table of contents, 2002 
16. Buseman CM, Wright WE and Shay JW: Is telomerase a viable target in cancer? Mutat Res 730: 90-97, 2012.

17. Melk A, Kittikowit W, Sandhu I, Halloran KM, Grimm P, Schmidt BMW and Halloran PF: Cell senescence in rat kidneys in vivo increases with growth and age despite lack of telomere shortening. Kidney Int 63: 2134-2143, 2003.

18. Li Y and Lerman LO: Cellular senescence: A new player in kidney injury. Hypertension 76: 1069-1075, 2020.

19. Kato S, Shiels PG, McGuinness D, Lindholm B, Stenvinkel P, Nordfors L, Qureshi AR, Yuzawa Y, Matsuo S and Maruyama S Telomere attrition and elongation after chronic dialysis initiation in patients with end-stage renal disease. Blood Purif 41: 25-33, 2016.

20. Perico N, Remuzzi G and Benigni A: Aging and the kidney. Curr Opin Nephrol Hypertens 20: 312-317, 2011.

21. Abdel-Rahman EM and Okusa MD: Effects of aging on renal function and regenerative capacity. Nephron Clin Pract 127: 15-20, 2014.

22. Wills LP and Schnellmann RG: Telomeres and telomerase in renal health. J Am Soc Nephrol 22: 39-41, 2011.

23. Blasco MA, Lee HW, Hande MP, Samper E, Lansdorp PM, DePinho RA and Greider CW: Telomere shortening and tumor formation by mouse cells lacking telomerase RNA. Cell 91: 25-34, 1997.

24. Wright WE and Shay JW: Telomere dynamics in cancer progression and prevention: Fundamental differences in human and mouse telomere biology. Nat Med 6: 849-851, 2000.

25. Kloda K, Domanski L, Kwiatkowska E, Borowiecka E, Safranow K, Drozd A, Ciechanowicz A, MaciejewskaKarłowska A, Sawczuk M, Pawlik A and Ciechanowski K: hTERT, BICD1 and chromosome 18 polymorphisms associated with telomere length affect kidney allograft function after transplantation. Kidney Blood Press Res 40: 111-120, 2015.

26. O'Hare AM, Bertenthal D, Walter LC, Garg AX, Covinsky K, Kaufman JS, Rodriguez RA and Allon M: When to refer patients with chronic kidney disease for vascular access surgery: Should age be a consideration? Kidney Int 71: 555-561, 2007.

27. Verzola D, Gandolfo MT, Gaetani G, Ferraris A, Mangerini R, Ferrario F, Villaggio B, Gianiorio F, Tosetti F, Weiss U, et al: Accelerated senescence in the kidneys of patients with type 2 diabetic nephropathy. Am J Physiol Renal Physiol 295: F1563-F1573, 2008

28. Lindeman RD, Tobin J and Shock NW: Longitudinal studies on the rate of decline in renal function with age. J Am Geriatr Soc 33: 278-285, 1985.

29. Chow WH, Dong LM and Devesa SS: Epidemiology and risk factors for kidney cancer. Nat Rev Urol 7: 245-257, 2010

30. Klatte T, Rossi SH and Stewart GD: Prognostic factors and prognostic models for renal cell carcinoma: A literature review. World J Urol 36: 1943-1952, 2018.

31. Morais M and Dias F, Teixeira AL and Medeiros R: Telomere length in renal cell carcinoma: The Jekyll and Hyde biomarker of ageing of the kidney. Cancer Manag Res 12: 1669-1679, 2020.

32. Pal D, Sharma U, Singh SK, Kakkar N and Prasad R: Inhibition of hTERT expression by MAP kinase inhibitor induces cell death in renal cell carcinoma. Urol Oncol 35: 401-408, 2017.

33. Wu X, Amos CI, Zhu Y, Zhao H, Grossman BH, Shay JW, Luo S, Hong WK and Spitz MR: Telomere dysfunction: A potential cancer predisposition factor. J Natl Cancer Inst 95: 1211-1218, 2003.

34. Mehle C, Ljungberg B and Roos G: Telomere shortening in renal cell carcinoma. Cancer Res 54: 236-241, 1994.

35. Gisselsson D, Gorunova L, Hoglund M, Mandahl N and Elfving P: Telomere shortening and mitotic dysfunction generate cytogenetic heterogeneity in a subgroup of renal cell carcinomas. Br J Cancer 91: 327-332, 2004.

36. Carrozza F, Santoni M, Piva F, Cheng L, Lopez-Beltran A, Scarpelli M, Montironi R, Battelli N and Tamberi S: Emerging immunotherapeutic strategies targeting telomerases in genitourinary tumors. Crit Rev Oncol Hematol 131: 1-6, 2018.

37. Svenson U, Ljungberg B and Roos G: Telomere length in peripheral blood predicts survival in clear cell renal cell carcinoma. Cancer Res 69: 2896-2901, 2009.

38. Demanelis K, Jasmine F, Chen LS, Chernoff M, Tong L, Delgado D, Zhang C, Shinkle J, Sabarinathan M, Lin H, et al: Determinants of telomere length across human tissues. Science 369: eaaz6876, 2020.

39. Aramburu T, Plucinsky S and Skordalakes E: POT1-TPP1 telomere length regulation and disease. Comput Struct Biotechnol J 18: 1939-1946, 2020.
40. Pal D, Singh SK, Kakkar N and Prasad R: Expression of telomere binding proteins (RAP1 and POT1) in renal cell carcinoma and their correlation with clinicopathological parameters. Indian J Clin Biochem 32: 301-305, 2017.

41. Dahse R, Fiedler W, Junker K, Schlichter A, Schubert J and Claussen U: Telomerase activity and telomere lengths: Alterations in renal cell carcinomas. Kidney Int 56: 1289-1290, 1999.

42. Sugimura K, Yoshida N, Hisatomi H, Nakatani T and Ikemoto S: Telomerase activity in human renal cell carcinoma. BJU Int 83 : 693-697, 1999

43. Tonelli M and Riella MC: Chronic kidney disease and the aging population. Kidney Int 85: 487-491, 2014

44. Kremers WK, Denic A, Lieske JC, Alexander MP, Kaushik V, Elsherbiny HE, Chakkera HA, Poggio ED and Rule AD: Distinguishing age-related from disease-related glomerulosclerosis on kidney biopsy: The aging kidney anatomy study. Nephrol Dial Transplant 30: 2034-2039, 2015.

45. Nitta K, Okada K, Yanai M and Takahashi S: Aging and chronic kidney disease. Kidney Blood Press Res 38: 109-120, 2013.

46. Cañadas-Garre M, Anderson K, Cappa R, Skelly R, Smyth LJ, McKnight AJ and Maxwell AP: Genetic susceptibility to chronic kidney disease-some more pieces for the heritability puzzle. Front Genet 10: 453, 2019.

47. Tonelli $\mathrm{M}$ and Riella M: Chronic kidney disease and the aging population. J Cross Cult Gerontol 29: 231-237, 2014.

48. Mazidi M, Rezaie P, Covic A, Malyszko J, Rysz J, Kengne AP and Banach M: Telomere attrition, kidney function, and prevalent chronic kidney disease in the United States. Oncotarget 8 80175-80181, 2017.

49. Kidir V, Aynali A, Altuntas A, Inal S, Aridogan B and Sezer MT: Telomerase activity in patients with stage $2-5 \mathrm{D}$ chronic kidney disease. Nefrologia 37: 592-597, 2017 (In English and Spanish).

50. Tsirpanlis G, Chatzipanagiotou S, Boufidou F, Kordinas V, Alevyzaki F, Zoga M, Kyritsis I, Stamatelou K, Triantafyllis G and Nicolaou C: Telomerase activity is decreased in peripheral blood mononuclear cells of hemodialysis patients. Am J Nephrol 26: 91-96, 2006.

51. Sell DR and Monnier VM: End-stage renal disease and diabetes catalyze the formation of a pentose-derived crosslink from aging human collagen. J Clin Invest 85: 380-384, 1990.

52. Wong LS, van der Harst P, de Boer RA, Codd V, Huzen J, Samani NJ, Hillege HL, Voors AA, van Gilst WH, Jaarsma T and van Veldhuisen DJ: Renal dysfunction is associated with shorter telomere length in heart failure. Clin Res Cardiol 98: 629-634, 2009.

53. Kooman JP, Dekker MJ, Usvyat LA, Kotanko P, van der Sande FM, Schalkwijk CG, Shiels PG and Stenvinkel P: Inflammation and premature aging in advanced chronic kidney disease. Am J Physiol Renal Physiol 313: F938-F950, 2017.

54. Hu MC, Kuro-o M and Moe OW: Klotho and chronic kidney disease. Contrib Nephrol 180: 47-63, 2013.

55. Vlassara H, Torreggiani M, Post JB, Zheng F, Uribarri J and Striker GE: Role of oxidants/inflammation in declining renal function in chronic kidney disease and normal aging. Kidney Int Suppl S3-11, 2009.

56. Wynn TA and Ramalingam TR: Mechanisms of fibrosis: Therapeutic translation for fibrotic disease. Nat Med 18: 1028-1040, 2012

57. Rockey DC, Bell PD and Hill JA: Fibrosis-a common pathway to organ injury and failure. N Engl J Med 372: 1138-1149, 2015.

58. Vaglio A, Salvarani C and Buzio C: Retroperitoneal fibrosis Lancet 367: 241-251, 2006.

59. Sziksz E, Pap D, Lippai R, Béres NJ, Fekete A, Szabó AJ and Vannay A: Fibrosis related inflammatory mediators: Role of the IL-10 cytokine family. Mediators Inflamm 2015: 764641, 2015.

60. Nowakowski ACH: Cystic fibrosis kidney disease: 10 Tips for clinicians. Front Med (Lausanne) 5: 242, 2018

61. Piñeiro-Hermida S, Autilio C, Martínez P, Bosch F, Pérez-Gil J and Blasco MA: Telomerase treatment prevents lung profibrotic pathologies associated with physiological aging. J Cell Biol 219: e202002120, 2020.

62. Sangaralingham SJ, Wang BH, Huang L, Kumfu S, Ichiki T, Krum $\mathrm{H}$ and Burnett JC Jr: Cardiorenal fibrosis and dysfunction in aging: Imbalance in mediators and regulators of collagen. Peptides 76: 108-114, 2016.

63. Cianciolo RE, Benali SL and Aresu L: Aging in the canine kidney. Vet Pathol 53: 299-308, 2016.

64. Naesens M: Replicative senescence in kidney aging, renal disease, and renal transplantation. Discov Med 11: 65-75, 2011. 
65. Turner KJ, Vasu V and Griffin DK: Telomere biology and human phenotype. Cells 8: 73, 2019.

66. Yang L, Besschetnova TY, Brooks CR, Shah JV and Bonventre JV: Epithelial cell cycle arrest in G2/M mediates kidney fibrosis after injury. Nat Med 16: 535-543, 531p following 143, 2010.

67. Ronco C, Bellomo R and Kellum JA: Acute kidney injury. Lancet 394: 1949-1964, 2019.

68. Ishani A, Xue JL, Himmelfarb J, Eggers PW, Kimmel PL Molitoris BA and Collins AJ: Acute kidney injury increases risk of ESRD among elderly. J Am Soc Nephrol 20: 223-228, 2009.

69. Epel ES, Lin J, Dhabhar FS, Wolkowitz OM, Puterman E, Karan L and Blackburn EH: Dynamics of telomerase activity in response to acute psychological stress. Brain Behav Immun 24: 531-539, 2010.

70. Kiecolt-Glaser JK and Glaser R: Psychological stress, telomeres, and telomerase. Brain Behav Immun 24: 529-530, 2010.

71. Cheng H, Fan X, Lawson WE, Paueksakon P and Harris RC: Telomerase deficiency delays renal recovery in mice after ischemia-reperfusion injury by impairing autophagy. Kidney Int 88: 85-94, 2015.

72. Zhan M, Brooks C, Liu F, Sun L and Dong Z: Mitochondrial dynamics: Regulatory mechanisms and emerging role in renal pathophysiology. Kidney Int 83: 568-581, 2013.

73. Lane RK, Hilsabeck T and Rea SL: The role of mitochondrial dysfunction in age-related diseases. Biochim Biophys Acta 1847: 1387-1400, 2015.

74. Volarevic V, Djokovic B, Jankovic MG, Harrell CR, Fellabaum C, Djonov V and Arsenijevic N: Molecular mechanisms of cisplatin-induced nephrotoxicity: A balance on the knife edge between renoprotection and tumor toxicity. J Biomed Sci 26: 25, 2019

75. Shin YJ, Kim TH, Won AJ, Jung JY, Kwack SJ, Kacew S, Chung KH, Lee BM and Kim HS: Age-related differences in kidney injury biomarkers induced by cisplatin. Environ Toxicol Pharmacol 37: 1028-1039, 2014.

76. Abdel-Kader K and Palevsky PM: Acute kidney injury in the elderly. Clin Geriatr Med 25: 331-358, 2009.

77. Aubert $G$ and Lansdorp PM: Telomeres and aging. Physiol Rev 88: 557-579, 2008.

78. Westhoff JH, Schildhorn C, Jacobi C, Hömme M, Hartner A, Braun H, Kryzer C, Wang C, von Zglinicki T, Kränzlin B, et al Telomere shortening reduces regenerative capacity after acute kidney injury. J Am Soc Nephrol 21: 327-336, 2010.

79. Schmitt R and Cantley LG: The impact of aging on kidney repair. Am J Physiol Renal Physiol 294: F1265-F1272, 2008.

80. Andrade L, Rodrigues CE, Gomes SA and Noronha IL: Acute kidney injury as a condition of renal senescence. Cell Transplant 27: 739-753, 2018

81. Pei Y: Diagnostic approach in autosomal dominant polycystic kidney disease. Clin J Am Soc Nephrol 1: 1108-1114, 2006.

82. Mangolini A, de Stephanis L and Aguiari G: Role of calcium in polycystic kidney disease: From signaling to pathology. World J Nephrol 5: 76-83, 2016

83. Perumareddi P and Trelka DP: Autosomal dominant polycystic kidney disease. Prim Care 47: 673-689, 2020

84. McConnachie DJ, Stow JL and Mallett AJ: Ciliopathies and the kidney: A review. Am J Kidney Dis: Oct 8, 2020 (Epub ahead of print).

85. Rangan GK, Tchan MC, Tong A, Wong AT and Nankivell BJ: Recent advances in autosomal-dominant polycystic kidney disease. Intern Med J 46: 883-892, 2016.

86. Iliuta IA, Kitchlu A and Pei Y: Methodological issues in clinical trials of polycystic kidney disease: A focused review. J Nephrol 30: 363-371, 2017.

87. Yaghoubian A, de Virgilio C, White RA and Sarkisyan G: Increased incidence of renal cysts in patients with abdominal aortic aneurysms: A common pathogenesis? Ann Vasc Surg 20: 787-791, 2006.

88. Kolatsi-Joannou M, Bingham C, Ellard S, Bulman MP, Allen LI, Hattersley AT and Woolf AS: Hepatocyte nuclear factor-1beta: A new kindred with renal cysts and diabetes and gene expression in normal human development. J Am Soc Nephrol 12: 2175-2180, 2001.

89. Ta MH, Schwensen KG, Liuwantara D, Huso DL, Watnick T and Rangan GK: Constitutive renal Rel/nuclear factor- $\kappa \mathrm{B}$ expression in lewis polycystic kidney disease rats. World J Nephrol 5: 339-357, 2016

90. Bergmann C, von Bothmer J, Ortiz Bruchle N, Venghaus A, Frank V, Fehrenbach H, Hampel T, Pape L, Buske A, Jonsson J, et al: Mutations in multiple PKD genes may explain early and severe polycystic kidney disease. J Am Soc Nephrol 22: 2047-2056, 2011.
91. Hian CK,Lee CL and Thomas W: Renin-angiotensin-aldosterone system antagonism and polycystic kidney disease progression. Nephron 134: 59-63, 2016.

92. Chapman AB: Autosomal dominant polycystic kidney disease: Time for a change? J Am Soc Nephrol 18: 1399-1407, 2007.

93. Zhang W, Tan AY, Blumenfeld J, Liu G, Michaeel A, Zhang T, Robinson BD, Salvatore SP, Kapur S, Donahue S, et al: Papillary renal cell carcinoma with a somatic mutation in MET in a patient with autosomal dominant polycystic kidney disease. Cancer Genet 209: 11-20, 2016

94. Gansevoort RT, Arici M, Benzing T, Birn H, Capasso G, Covic A, Devuyst O, Drechsler C, Eckardt KU, Emma F, et al: Recommendations for the use of tolvaptan in autosomal dominant polycystic kidney disease: A position statement on behalf of the ERA-EDTA working groups on inherited kidney disorders and european renal best practice. Nephrol Dial Transplant 31: 337-348, 2016

95. Riwanto M, Kapoor S, Rodriguez D, Edenhofer I, Segerer S and Wuthrich RP: Inhibition of aerobic glycolysis attenuates disease progression in polycystic kidney disease. PLoS One 11: e0146654, 2016.

96. Ta MH, Schwensen KG, Foster S, Korgaonkar M, Ozimek-Kulik JE, Phillips JK, Peduto A and Rangan GK: Effects of TORC1 inhibition during the early and established phases of polycystic kidney disease. PLoS One 11: e0164193, 2016.

97. Couillard M, Guillaume R, Tanji N, D'Agati V and Trudel M c-myc-induced apoptosis in polycystic kidney disease is independent of FasL/Fas interaction. Cancer Res 62: 2210-2214, 2002.

98. Raina R, Lou L, Berger B, Vogt B, Sao-Mai Do A, Cunningham R, Vasavada P, Herrmann K, Dell K and Simonson M: Relationship of urinary endothelin-1 with estimated glomerular filtration rate in autosomal dominant polycystic kidney disease: A pilot cross-sectional analysis. BMC Nephrol 17: 22, 2016.

99. Kocer D, Karakukcu C, Ozturk F, Eroglu E and Kocyigit I: Evaluation of fibrosis markers: Apelin and transforming growth factor- $\beta 1$ in autosomal dominant polycystic kidney disease patients. Ther Apher Dial 20: 517-522, 2016

100. Martins DP, Souza MA, Baitello ME, Nogueira V, Oliveira CI, Pinhel MA, Caldas HC, Filho MA and Souza DR: Vascular endothelial growth factor as an angiogenesis biomarker for the progression of autosomal dominant polycystic kidney disease. Genet Mol Res 15: 2016.

101. Peda JD, Salah SM, Wallace DP, Fields PE, Grantham CJ, Fields TA and Swenson-Fields KI: Autocrine IL-10 activation of the STAT3 pathway is required for pathological macrophage differentiation in polycystic kidney disease. Dis Model Mech 9: 1051-1061, 2016

102. de Melo AS, Dias SV, Cavalli Rde C, Cardoso VC, Bettiol H, Barbieri MA, Ferriani RA and Vieira CS: Pathogenesis of polycystic ovary syndrome: Multifactorial assessment from the foetal stage to menopause. Reproduction 150: R11-R24, 2015.

103. Borie R, Kannengiesser C, Dupin C, Debray MP, Cazes A and Crestani B: Impact of genetic factors on fibrosing interstitial lung diseases. Incidence and clinical presentation in adults. Presse Med 49: 104024, 2020.

104. Ballew BJ and Savage SA: Updates on the biology and management of dyskeratosis congenita and related telomere biology disorders. Expert Rev Hematol 6: 327-337, 2013.

105. Li H, Zhang Y, Dan J, Zhou R, Li C, Li R, Wu X, Singh SK, Chang JT, Yang J and Luo Y: p53 mutation regulates PKD genes and results in co-occurrence of PKD and tumorigenesis. Cancer Biol Med 16: 79-102, 2019

106. Duffy MJ, Synnott NC, O'Grady S and Crown J: Targeting p53 for the treatment of cancer. Semin Cancer Biol: Jul 30, 2020 (Epub ahead of print)

107. Sugarman ET, Zhang G and Shay JW: In perspective: An update on telomere targeting in cancer. Mol Carcinog 58: 1581-1588, 2019.

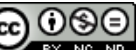

This work is licensed under a Creative Commons Attribution-NonCommercial-NoDerivatives 4.0 International (CC BY-NC-ND 4.0) License. 